\title{
Revista
}

(Ropp) Gestão \& Políticas Públicas

Artigo

\section{Avaliação do Desempenho das Unidades da Fundação Hemominas por meio da Análise Envoltória de Dados}

\author{
Performance evaluation of Hemominas Foundation Units Through Data \\ Envelopment Analysis
}

La Evaluación del Desempeño de Hemominas Fundación Unidades a través de Análisis Envolvente de Datos.

Sunao Leonardo Koga', Leonardo Fernando Cruz Basso ${ }^{2}$, Herbert Kimura ${ }^{3}$

\footnotetext{
1 Filiação institucional. Gerente administrativo da Fundação Hemominas (Unidade Uberlândia) e docente em Gestão da Produção do Grupo Pitágoras, Uberlândia, MG, Brasil.

Correspondência: E-mail: sunaoleonardo@terra.com.br Instituição de correspondência

Fundação Hemominas

Av. Levino de Souza, 1845 - Umuarama - Uberlândia - 38405-322 - MG - Brasil

2 Filiação institucional. Possui graduação em Engenharia Mecânica pelo Instituto Tecnológico da Aeronáutica, mestrado e doutorado em Economia pela New School for Social Research, NY, EUA. Atualmente é professor titular da Universidade Mackenziee, Brasil.

Correspondência: E-mail: leonardobasso@mackenzie.br Instituição de correspondência

Universidade Presbiteriana Mackenzie - Faculdade de Ciências Econômicas Administrativas e Contábeis.

Asa Norte - Brasília - 70910-900 - DF - Brasil.

${ }^{3}$ Filiação institucional. Possui Graduação em Engenharia Eletrônica pelo Instituto Tecnológico de Aeronáutica, mestrado em Estatística e doutorado em Administração pela Universidade de São Paulo e doutorado em Administração de Empresas pela Fundação Getulio Vargas, Brasil.

Correspondência: E-mail: herbert.kimura@gmail.com Instituição de correspondência

Universidade de Brasília

Rua Rio Grande do Norte, 300 - Funcionários - Belo Horizonte - 30.130-13 - MG - Brasil
} 
Resumo

O desempenho organizacional no âmbito governamental pode ser explanado em relação aos serviços ofertados como gestão eficaz, redução de custos e benefícios ao cliente/usuário/cidadão. A análise do desempenho das instituições públicas é condição precípua para a tomada de decisão endógena e exógena, bem como na formulação e implementação de políticas públicas eficientes. A Análise Envoltória de Dados (DEA) traduz eficientemente este posicionamento no contexto da eficiência técnica, de escala e alocativa ao identificar as unidades produtivas eficientes e ineficientes. Este artigo busca contribuir na discussão de eficiência das Unidades da F. Hemominas em Minas Gerais, fazendo uma classificação de eficiência utilizando a DEA e ainda, verificar o grau de paridade entre eficiência operacional e eficiência financeira. Na análise de eficiência operacional utilizando a DEA, utilizamos como Inputs, o volume total de sangue coletado, número de empregados e a despesa com insumos, como Outputs utilizamos total de hemocomponentes produzidos, total de hemocomponentes descartados e total de serviços clínicos efetuados. Para eficiência financeira, os Inputs foram, a despesa total menos a despesa com pessoal, a despesa com pessoal dividida pelo número de funcionários, para os Outputs utilizamos a receita arrecadada e as despesas orçamentárias executadas. Os resultados demonstraram fraca significância estatística entre eficiência operacional e eficiência financeira. Almejamos que os resultados sirvam como substrato de análise e discussão pelos gestores das unidades averiguadas e da F.H. no que concerne ao uso, alocação e disposição eficiente do erário com vistas a salvar vidas e atender os clientes/usuários/cidadãos que necessitam dos serviços especializados e hemocomponentes.

Palavras-chave: Avaliação de Desempenho, Aprendizagem, Eficiência Técnica, DEA, Serviço Público.

\section{Abstract}

The organizational performance within government can be explained in relation to the services offered as effective management, cost savings and benefits to the client/user/citizen. The analysis of the 
performance of public institutions is essential condition for the decision making endogenous and exogenous, as well as in the formulation and implementation of effective public policies. The data envelopment analysis (DEA) effectively translates this position in the context of technical efficiency, scale and allocative to identify efficient and inefficient production units. This article seeks to contribute to the discussion of efficiency units of F. Hemominas in Minas Gerais, making an efficiency rating using the DEA and even check the degree of parity between operational and financial efficiency. In the analysis of operational efficiency using DEA, we used as inputs, the total volume of blood collected, number of employees and the expense of inputs, outputs and full use of blood products produced, full of blood discarded and total clinical services performed. For financial efficiency, the inputs were, total spending less personnel expenses, personnel expenses divided by the number of employees for the Outputs use the revenue collected and expenditure budget executed. The results showed weak statistical significance between operational efficiency and financial efficiency. We aim that the results serve as a substrate for analysis and discussion by the managers of the units investigated and $\mathrm{FH}$ regarding the use, allocation and efficient disposition of the treasury in order to save lives and serve customers/users/citizens in need of specialized services and blood products.

Keywords: Performance Assessment, Learning, Technical Efficiency, DEA, Public Service.

Resumen El análisis de desempeño de las instituciones públicas es condición precipua para la tomada de decisión endógena y exógena, bien cómo en la formulación e implementación de políticas públicas eficientes. El Análisis Envolvente de Dados (DEA) traduce eficientemente este posicionamiento en el contexto de la eficiencia técnica, de escala y asignativa al identificar las unidades productivas eficientes e ineficientes. Este artículo busca contribuir en la discusión de eficiencia de las Unidades de la F. Hemominas en Minas Gerais, haciendo una 
clasificación de eficiencia utilizando el DEA y verificar el grado de paridad entre eficiencia operacional y eficiencia financiera. En el análisis de eficiencia operacional utilizando a DEA, utilizamos como Inputs, el volumen total de sangre colectada, número de empleados y el coste con insumos, como Outputs utilizamos total de hemocomponentes producidos, total de hemocomponentes descartados e total de servicios clínicos efectuados. Para eficiencia financiera, los Inputs fueran, el coste total menos el coste con personal, el coste con personal dividida por el número de funcionarios, para los Outputs utilizamos a receta recaudada y los costes presupuestarios ejecutados. Los resultados demostraran una débil significancia estadística entre eficiencia operacional y eficiencia financiera. Anhelamos que los resultados sirvan como substrato de análisis y discusión por los gestores de las unidades averiguadas y de la F.H. en el que concieme al uso, asignación e disposición eficiente del erario con vistas a salvar vidas y atender los clientes/usuarios/ciudadanos que necesitan de los servicios especializados y hemocomponentes.

Palabras clave: Evaluación de Desempeño, Aprendizaje, Eficiencia Técnica, DEA, Servicio Público. 


\section{Introdução}

A gestão pública no Brasil vem sofrendo transformações relevantes nas últimas duas décadas, principalmente a partir da introdução de um modelo de gestão gerencial no final dos anos 1990, que almejava a administração do erário público de forma eficiente e com informações transparentes. Para atingir esses objetivos de eficiência e transparência, o Estado tem buscado qualificar seus gestores no processo de planejamento, controle e gestão, introduzindo e monitorando indicadores de desempenho pactuados em contratos. Tais mecanismos de avaliação de desempenho devam levar em consideração objetivos e anseios de governos, políticos, burocratas, agentes econômicos privados e cidadãos.

Assim, a avaliação de desempenho por parte do Estado tem como objetivo essencial a aferição da eficiência com que agentes ou agência de serviços públicos traduz, em termos de resultados tangíveis ou intangíveis, o investimento financeiro ou econômico realizado. Adicionalmente, a avaliação de desempenho permite analisar o alinhamento entre os resultados dos projetos às metas do programa em questão.

De acordo com Kettl (1996), a avaliação de desempenho deve ocorrer em duas frentes considerando-se tanto produtos quanto resultados. Sob a perspectiva de produtos, pode-se analisar o modelo de gerenciamento dos gestores públicos frente aos insumos disponíveis, obtendo-se explicação de problemas que se reflitam nos resultados. Sob a perspectiva de resultados, pode-se compreender a efetividade de um programa possibilitando 0 aprimoramento de estratégias, uma vez que produtos e resultados estão fortemente interrelacionados (Kettl, 1996).

A partir das indicações identificadas na avaliação de desempenho, eventuais transformações e reestruturações, por meio de novas formas de administrar o setor público (BRESSER, 1998) podem indicar respostas para melhor capacitar o Estado na execução de políticas públicas, permitindo a oferta de bens e serviços sociais de boa qualidade.

Para Rezende (2002), grande parte das políticas de reforma administrativa, as quais estão sendo impetradas, têm um foco no aumento do nível de desempenho dos serviços públicos. A maior flexibilidade na gestão, a descentralização estratégica e a redução da dicotomia no processo decisório dos serviços públicos constituem as estruturas relevantes de reformas (Rezende, 2002).

Assim, a busca por eficiência técnica e econômica das agências e instituições públicas deve ser almejada e analisada. Em particular a utilização de mecanismos e ou metodologias na avaliação do desempenho dessas estruturas deve ser fomentada e aprimorada.

Nesse contexto, esse trabalho investiga o grau de relacionamento linear entre eficiência financeira e eficiência operacional no escopo das instituições públicas. O estudo analisa o uso eficiente do erário na aquisição de insumos, produtos e serviços, bem comosua utilização, disposição e grau de otimização. Mais especificamente, a pesquisa foca em eficiência operacional e financeira no setor público em unidades da Fundação Hemominas.

Considerando a ótica governamental, em qualquer das instâncias e estruturas públicas, o estudo análise permite avaliar a implantação de políticas de redução de custos, por meio da detecção de recursos ociosos ou inutilizados. Além disso, o estudo propicia avaliar alternativas de otimização derecursos utilizados ou produtos e serviços ofertados ao 
cidadão. $\quad$ trabalho também fornece subsídios aos gestores na identificação de unidades ineficientes e indica mudanças necessárias nos níveis de insumos e produtos para que as unidades se tornem eficientes.

Deve-se enfatizar que uma ampla pesquisa em bancos de dados on-line e na Internet identificou poucos trabalhos no escopo da presente pesquisa, sendo que os estudos encontrados são prioritariamente internacionais, conforme apresentado no Quadro 1. Os resultados desse levantamento bibliográfico sugere uma lacuna de conhecimento sobre nível de eficiência no setor público brasileiro, mais particularmente, na área de bancos de sangue.

Quadro 1. Trabalhos Internacionais encontrados período 1992 -2012

\begin{tabular}{|c|c|c|c|}
\hline Titulo & Autor(ES) & Publ.em & Mod.Utl \\
\hline $\begin{array}{l}\text { Using Data Envelopment Analysis } \\
\text { and translog methods to investigate } \\
\text { blood center operations: efficiency, }\end{array}$ & HAO, S.. WALLACE,E. & 1992 & $\begin{array}{l}\text { DEA E } \\
\text { TRANSL } \\
\text { OG }\end{array}$ \\
\hline $\begin{array}{l}\text { Cost of Allogeneic and Autologous } \\
\text { Blood Transfusion in Canadá }\end{array}$ & $\begin{array}{l}\text { TRETIAK,R.; LAUPACIS,A.; } \\
\text { RIVIERE,M.; MCKERRACHER,K.; } \\
\text { SOUETRE,E. ; the Canadian Cost of } \\
\text { Transfusion Study Groupp* }\end{array}$ & 1996 & $\begin{array}{l}\text { Análise } \\
\text { estrut.e } \\
\text { custos }\end{array}$ \\
\hline $\begin{array}{l}\text { Alleviating blood shortages in a } \\
\text { resource-constrained environment }\end{array}$ & PITOCCO C., Sexton TR & 2005 & $\begin{array}{l}\text { DEA } \\
\text { CRS-VRS }\end{array}$ \\
\hline $\begin{array}{l}\text { Economies of scale in blood banking: } \\
\text { a study based on data envelopment }\end{array}$ & PEREIRA, A. & 2006 & $\begin{array}{l}\text { DEA } \\
\text { CRS-VRS }\end{array}$ \\
\hline $\begin{array}{l}\text { International comparison of the } \\
\text { technical efficiency of component }\end{array}$ & $\begin{array}{l}\text { VEIHOLA,M.; AROVIITA,P.; LINNA,M.; } \\
\text { SINTONEN,H.; KEKOMÄKI,R. }\end{array}$ & 2006 & $\begin{array}{l}\text { DEA } \\
\text { CRS-VRS }\end{array}$ \\
\hline $\begin{array}{l}\text { Discarded cellular components and } \\
\text { the technical efficiency of }\end{array}$ & $\begin{array}{l}\text { VEIHOLA,M.; AROVIITA,P.; LINNA,M.; } \\
\text { SINTONEN,H.; KEKOMÄKI,R. }\end{array}$ & 2007 & $\begin{array}{l}\text { DEA } \\
\text { CRS-VRS }\end{array}$ \\
\hline $\begin{array}{l}\text { Working hours and produced cellular } \\
\text { components as variables } \\
\text { to evaluate blood bank efficiency }\end{array}$ & $\begin{array}{l}\text { VEIHOLA,M.; AROVIITA,P.; LINNA,M.; } \\
\text { SINTONEN,H.; KEKOMÄKI,R. }\end{array}$ & 2008 & $\begin{array}{l}\text { DEA } \\
\text { CRS-VRS }\end{array}$ \\
\hline
\end{tabular}

Fonte: adaptado pelo autor dos bancos de dados on-line e internet.

Considerando seu objetivo, o presente trabalho está alicerçado na comparação dos dados financeiros e produtivos das unidades que compõe a Fundação Hemominas, e busca avaliar, por meio da análise envoltória de dados - DEA, o relacionamento entre eficiência financeira e eficiência operacional. As variáveis de insumos e produtos a serem incluídas no 
modelo da DEA, são definidos a partir do referencial teórico, obtido em pesquisa na literatura nacional e internacional.

A partir do levantamento bibliográfico, a seguinte hipótese foi construída em relação ao problema delineado: "Existe correlação positiva entre eficiência financeira e eficiência operacional das unidades da Fundação Hemominas."

Quadro 2. Relação das unidades da Fundação Hemominas

\begin{tabular}{|c|c|c|c|c|c|c|c|}
\hline $\mathbf{N r}$ & Unidade & Sigla & Unidade & Sigla & Unidade & Sigla & Unidade \\
\hline 01 & DMU01 & 06 & DMU06 & 11 & DMU11 & 16 & DMU16 \\
02 & DMU02 & 07 & DMU07 & 12 & DMU12 & 17 & DMU17 \\
03 & DMU03 & 08 & DMU08 & 13 & DMU13 & 18 & DMU18 \\
04 & DMU04 & 09 & DMU09 & 14 & DMU14 & 19 & DMU19 \\
05 & DMU05 & 10 & DMU10 & 15 & DMU15 & 20 & DMU20 \\
\hline
\end{tabular}

Assim, o objetivo geral deste trabalho consiste em avaliar as unidades da Fundação Hemominas, apresentadas no Quadro 2, por meio da DEA, de forma a propiciar informações sobre o grau de correlação entre eficiência financeira e operacional. Os objetivos específicos da pesquisa envolvem (i) a geração de uma classificação das unidades da Fundação Hemominas analisadas no que concerne à eficiência operacional e financeira e (ii) a definição de um modelo que possa auxiliar na análise do grau de eficiência relativa de unidades que gerenciam bancos de sangue.

\section{Referencial Teórico}

O desempenho de empresas ou unidades de negócios pode ser realizada a partir de várias perspectivas. Em especial, levando-se em consideração a disponibilidade de dados, mecanismos baseados em contabilidade e em economia podem ser utilizados.

De acordo com Carton e Hofer (2006), a contabilidade, por meio de relatórios e de indicadores padrões possibilita a comparação entre empresas similares e permite a tomada de decisão pelos gestores dentro dos contextos considerados.

Os mecanismos contábeis estabelecem medidas de desempenho e eficácia organizacional, subsidiando usuários sobre informações referentes ao patrimônio e suas mutações, bem como sobre resultados de análises horizontal e vertical e sobre indicadores contábeis que podem ser classificados em grupos econômico-financeiro e de desempenho operacional (ludícibus, 2002).

Sob a perspectiva econômica, Barney (2002) argumenta que existe uma relação entre o valor do uso dos ativos e o valor criado pelo uso destes ativos. Essa relação, associada ao desempenho organizacional, estabelece quem um desempenho normal, o valor criado depende do valor consumido no uso dos ativos, sendo o lucro de uma organização ligado ao valor adicional em relação ao exigido pelos fornecedores de capital. 
Outra abordagem econômica para análise de desempenho está ligada aos fatores de produção. Considerando essa perspectiva de análise. Recorre-se ao conceito econômico da função de produção estática analisando-se comparativamente os insumos como, por exemplo, mão-de-obra, máquinas, matéria-prima, energia, etc. e os produtos gerados no processo de transformação (Ferreira, 2009).

Para Varian (1997), o desempenho está relacionado à função de produção que, por sua vez, é condicionada pela quantidade de fatores de produção. Pontos indicativos de combinações dos fatores produtivos que geram o mesmo nível de produção delimitam uma fronteira eficiente.

$\mathrm{Na}$ fronteira eficiente identifica-se a quantidade máxima que se pode obter de um produto, a partir de uma determinada combinação de fatores de produção (Ferreira, 2009). A quantidade máxima do produto está ligada a dois conceitos de eficiência (Ferreira, 2009); (i) técnica, associada a um processo de produção que utiliza a menor quantidade de insumos, considerando-se um mesmo nível de produção, (ii) econômica ou alocativa, associada a um processo que induz uma produção de um mesmo nível que o de outros processos, com um menor custo possível.

A combinação dos fatores de produção pode ser, considerando o nível de produção dado, convencionada como orientada a Insumos ou a Produtos (Peña, 2008). Dentro do contexto de mecanismos de análise de desempenho considerando-se insumos e produtos, destaca-se a DEA. Sua origem pode ser atribuída ao trabalho de Farrel (1957), que explorava métodos para avaliar a produtividade, por meio da análise de atividades (Ferreira, 2009). De acordo com Cooper, Seiford e Zhu (2004), o trabalho de Farrel (1957) envolvia a análise de um único produto prevenindo-se a utilização em situações de múltiplos produtos nas quais havia um conjunto de dados mais numerosos.

A partir do estudo de Rhodes (1978), a DEA ganhou maior robustez para análises que incluíam diversas variáveis de insumo e produto. O trabalho de Rhodes (1978) tinha por objetivo comparar a eficiência técnica das escolas públicas norte- americanas, comparando as participantes e as não-participantes de uma iniciativa governamental voltada à educação. Nesse contexto, Rhodes (1978) utilizou a DEA para avaliar eficiência relativa, buscando-se obter padrões de excelência que serviriam de benchmarks, a partir de uma amostra de escolas, denominadas de organizações produtivas, ou DMUs (Decision Making Units). Devese enfatizar, conforme argumenta (Ferreira, 2009), que uma das vantagens da análise de posicionamento competitivo ou desempenho relativo, baseando-se em benchmark por meio do DEA, envolve a falta de necessidade de se estabelecer relações funcionais entre insumos e resultados.

Assim, a análise por meio do DEA consiste em um método de pesquisa operacional, fundamentada em programação linear não-paramétrica, que permite a mensuração de eficiência técnica, de escala e alocativa de DMUs, considerando-se um conjunto multivariado de recursos e resultados (Pereira, 1995).

O estudo de Cooper (1970) estabeleceu o modelo CCR (abreviatura de Charnes, Cooper e Rhodes), generalizando a proposta de Farrel (1957) de um único produto e um único insumo, definindo um modelo de múltiplos produtos e múltiplos insumos (CHARNES et al, 1997).

O modelo CCR possibilita uma análise com retornos constante de escala (CRS Constant Returns to Scale), tendo sido alterado por Banker, Chames e Cooper (1984) para 
avaliar retornos variáveis de escala (VRS - Variable Returns to Scale), passando a ser denominado BCC (abreviatura de Banker, Chames e Cooper).

As diferenças fundamentais entre o CCR e o BCC estão associadas à superfície de envelopamento, estabelecendo-se combinações e suposições distintas sobre o retorno de escala e sobre o tipo de projeção do plano em relação à fronteira (Paiva, 2000). De acordo com Paiva (2000), os modelos CCR e BCC podem ter (i) orientação voltada para os produtos, na qual as projeções do plano observado sobre a fronteira envolvem a maximização equipropocional da produção dado o consumo, ou (ii) orientação voltada para os insumos, na qual busca-se a minimização equipropocional do consumo dada a produção.

É importante enfatizar que a metodologia DEA tem sido amplamente utilizada em estudos a nível internacional e nacional em vários segmentos como, por exemplo, bancário, educacional, de energia, farmacêutico, de produção, hospitalar, de investimentos, tecnológico e setor público.

Todavia, considerando-se estudos específicos de DEA aplicados a bancos de sangue públicos e privados foram encontrados apenas 7 trabalhos no período de 1992 a 2012, todos trazendo o contexto internacional. Assim, o presente estudo, ao abordar o contexto nacional, possibilita investigar a aplicabilidade da DEA para mensurar eficiência de bancos de sangue do setor público no Brasil.

Tendo em vista a aplicação específica do DEA a bancos de sangue da Fundação Hemominas, é importante caracterizar o programa mineiro no âmbito da política brasileira para o segmento. Com o objetivo de atender às diretrizes do Programa Nacional do Sangue e Hemoderivados (Pró-Sangue), foi estabelecida em 1985 a Fundação Centro de Hematologia e Hemoterapia de Minas Gerais - Fundação Hemominas. A Fundação Hemominas é unidade integrante da Fundação Hospitalar do Estado de Minas Gerais - FHEMIG.

Em 1987, a Fundação Hemominas iniciou a abertura de postos de coleta e processamento, em Montes Claros e em Governador Valadares. Em 1988, posto de coleta e

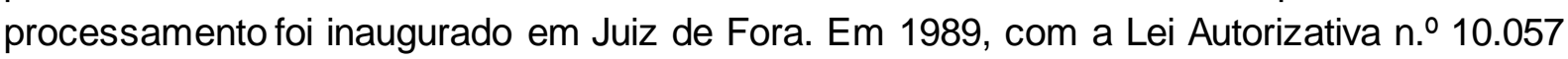
de 26 de dezembro de 1989, a Fundação Hemominas passa a ter responsabilidade jurídica de direito público, vinculada à Secretaria Estadual de Saúde de Minas Gerais. Sob essa forma de organização, a Fundação Hemominas tem como objetivo administrar o sistema hemoterápico e hematológico do estado de Minas Gerais e, mais especificamente, gerir o atendimento à demanda de transfusão de sangue de hospitais públicos e privados.

Em 1990, é estabelecida a ordenação dos serviços de hemoterapia, por meio da Política Nacional de Sangue, integrante da Política Nacional de Saúde. Entre 1990 e 2002, são abertas várias unidades de banco de sangue, para propiciar uma maior cobertura dos serviços hemoterápicos, avançando-se estrategicamente para o interior do estado de Monas Gerais. Atualmente, a Fundação Hemominas contempla 23 unidades e uma administração central, sendo responsável por atender cerca de $90 \%$ da demanda transfusional do estado de Minas Gerais. Destaca-se que a Fundação Hemominas é referência nacional em hemoterapia e hematologia. 


\section{Aplicação do Modelo}

\subsection{Análise e Seleção de Variáveis}

A abordagem de seleção de variáveis para a inclusão na DEA não segue uma metodologia padronizada. Em várias situações, a opinião de especialistas ou a abrangência de dados serve como referência para a escolha das variáveis a serem incorporadas nos modelos. Thanassoulis (1996) analisa esses mecanismos de escolha de variáveis e seus impactos no resultado de estudos de eficiência.

Bowlin (1998) estabelece que a seleção adequada das variáveis de insumos e produtos e fundamental, uma vez que a interpretação dos resultados da análise DEA, bem como sua aceitação pelos gestores e partes interessadas decorrem dessa escolha.

Outro ponto a considerar na modelagem prática da DEA envolve a utilização de um número restrito de variáveis, consideradas as mais relevantes, (FERREIRA, 2009), uma vez que o uso indiscriminado de variáveis comumente induz um aumento das métricas de eficiência das DMU's estudadas.

É importante também considerar, seguindo Fitzsimmons e Fitzsimmons (2000), que o dobro da quantidade de insumos e produtos não deve ser superar o número de unidades avaliadas. Na modelagem, deve-se observar ainda o grau de relação causal entre produtos e insumos. Assim, no presente estudo, as variáveis de Insumos e Produtos foram selecionadas seguindo, em um primeiro estágio, critério com base na literatura vigente e nos artigos publicados nos últimos 20 anos no segmento de bancos de sangue. As variáveis de maior concentração de análise por parte dos autores dos 7 trabalhos internacionais encontradas são apresentadas no Quadro 3.

Quadro 3. Frequência variáveis Insumose Produtos nos artigos internacionais período 1992-2012

\begin{tabular}{|l|c|l|c|}
\hline \multicolumn{1}{|c|}{ Insumo } & Qt & \multicolumn{1}{|c|}{ Produto } & Qt \\
\hline Volume de sangue total coletado & 3 & Concentrado de hemácias produzidos & 3 \\
Custo Operacional & 3 & Hemocomponentes produzidos & 3 \\
Empregados em tempo integral & 2 & Plaquetas produzidas & 3 \\
Horas de trabalho & 2 & Total de sangue coletado & 1 \\
Soma depreciação e encargos de juros & 1 & Plasma fresco congelado & 1 \\
Soma dos materiais e custos & 1 & Serviços clínicos especializados & 1 \\
suprimentos & 1 & Serviços de laboratório & 1 \\
Orçamento & 1 & especializados & \\
Instalações & 1 & & \\
Equipamentos & 1 & & \\
Plaqueta aférese & 1 & & \\
Concentrado de hemácia descartado & 1 & & \\
Plaqueta descartada & & \\
Fonte: adaptado pelo autor de HAO, S.; WALLACE, E, 1992; LAUPACIS, A. et al, 1996; PTOCCO, C.; SEXTON, TR., 2005; \\
PEREIRA, A., 2006; MARKEITA, V. et al, 2006, 2008
\end{tabular}


A frequência com que as variáveis aparecem nos estudos serviram de referência, para uma posterior análise e comparação para a seleção, no segundo estágio, de acordo com o contexto das unidades da Fundação Hemominas. As variáveis e seus respectivos dados, partindo-se da situação particular da Fundação, foram extraídas dos relatórios abaixo discriminados.

- Relatório/consolidado de candidatos a doação, hemocomponentes produzidos e transfundidos das unidades da Fundação Hemominas ano base 2012

- Demonstrativo de custos das unidades da Fundação Hemominas ano base 2012

- Relatório consolidado de perdas hemocomponentes das unidades da Fundação Hemominas 2012

- Relatório quantitativo do quadro humano e suas variações no ano 2012 da Fundação Hemominas.

Destes relatórios foram retiradas as seguintes variáveis operacionais e financeiras para Insumos (I) e Produtos (O) constantes nos Quadros 4 e 5.

Quadro 4. Variáveis operacionais Insumos e Produtos

\begin{tabular}{|c|c|}
\hline \multicolumn{2}{|r|}{ Operacional } \\
\hline Insumo & Descrição \\
\hline $\begin{array}{l}\text { Volume total de sangue } \\
\text { coletado }\end{array}$ & Quantitativo total de bolsas de sangue coletados em cada unidade \\
\hline Nr de empregados & $\begin{array}{l}\text { Total de funcionários de cada unidade que compreende os } \\
\text { concursados, recrutamento amplo, contratados e cedidos dos } \\
\text { órgãos estaduais e municipais com ônus. }\end{array}$ \\
\hline Dispêndios & $\begin{array}{l}\text { Gastos com materiais de uso direto no processo de coleta e } \\
\text { processamento }\end{array}$ \\
\hline \multicolumn{2}{|r|}{ Provovouris } \\
\hline $\begin{array}{l}\text { Total de Hemocomponentes } \\
\text { produzidos }\end{array}$ & $\begin{array}{l}\text { Soma dos sub-produtos derivados do sangue total: Conc. de } \\
\text { Hemácias, Conc. de Plaquetas, Plasma. }\end{array}$ \\
\hline $\begin{array}{l}\text { Total hemocomponentes } \\
\text { descartados }\end{array}$ & $\begin{array}{l}\text { Hemocomponentes produzidos e não utilizados por rompimento da } \\
\text { bolsa, validade e outros motivos }\end{array}$ \\
\hline Serviços clínicos efetuados & $\begin{array}{l}\text { Totais de exames laboratoriais realizados e as consultas médicas } \\
\text { efetuadas de cada unidade }\end{array}$ \\
\hline
\end{tabular}

Fonte: Adaptado pelo autor dos relatórios da Fundação Hemominas 2012

Quadro 5. Variáveis financeiras Insumos e Produtos

\begin{tabular}{|c|c|}
\hline \multicolumn{2}{|r|}{ Financeiro } \\
\hline Insumo & Descrição \\
\hline $\begin{array}{l}\text { Despesa com pessoal/ } n^{\circ} \text { de } \\
\text { funcionários }\end{array}$ & $\begin{array}{l}\text { Gasto com pessoal dividido pelo número de funcionários de cada } \\
\text { unidade }\end{array}$ \\
\hline Despesa orçada fixada & $\begin{array}{l}\text { Orçamento determinado no final de cada exercício para o } \\
\text { exercício seguinte com base nos gastos anteriores e } \\
\text { disponibilidade orçamentária futura (Lei Federal } 4.320 / 64 \text { ) }\end{array}$ \\
\hline $\begin{array}{l}\text { Despesa totalizada - despesa } \\
\text { com RH }\end{array}$ & $\begin{array}{l}\text { Soma dos gastos (materiais, equipamentos e gastos gerais) } \\
\text { subtraída a despesa com recursos humanos }\end{array}$ \\
\hline Produto & \\
\hline Receita arrecadada & $\begin{array}{l}\text { Receita arrecadada referente ao sistema SUS e privado. (Lei } \\
\text { federal } 10.205 / 01 \text { ) }\end{array}$ \\
\hline Despesa orçada executada & $\begin{array}{l}\text { Corresponde as despesas orçadas, devidamente empenhadas } \\
\text { liquidadas e pagas no final do exercício corrente. (Lei Federal } \\
4.320 / 64 \text { ) }\end{array}$ \\
\hline
\end{tabular}

Fonte: Adaptado pelo autor dos relatórios da Fundação Hemominas 2012 
Estas variáveis foram selecionadas por demonstrarem o grau de eficiência produtiva e financeira de cada unidade em conformidade com os artigos analisados. Outro ponto considerado no âmbito financeiro foi a relação entre gasto, receita e subsidio. Os itens de despesas compreendem insumos necessários para gerar receita em conjunto com orçamento executado, sendo este último, um resultado ou um produto da execução orçamentária.

\subsection{Construção de Modelos}

O modelo DEA estabelecido para análise das variáveis operacionais e financeiras foi o BCC-I e BCC-O, com o objetivo de verificar as duas vertentes no contexto da minimização dos Insumos e maximização dos Produtos. As variáveis operacionais e financeiras e seus respectivos dados coletados e tabulados por DMUs estão disponibilizados sequencialmente na Tabela 1 e Tabela 2.

Tabela 1 - Consolidado de produção por Unidades da Fundação Hemominas

\begin{tabular}{cccccccc}
\hline DMU & $\begin{array}{c}\text { (I) VI tot } \\
\text { sangue } \\
\text { col }\end{array}$ & $\begin{array}{l}\text { (I) Nr } \mathbf{~ N r} \\
\text { func. }\end{array}$ & \multicolumn{2}{l}{ (I) desp insumos } & $\begin{array}{c}\text { (O)Tot } \\
\text { hemoc } \\
\text { prod }\end{array}$ & $\begin{array}{c}\text { (O)Tot } \\
\text { hemoc } \\
\text { descart }\end{array}$ & $\begin{array}{c}\text { (O) serv } \\
\text { clínicos } \\
\text { ef. }\end{array}$ \\
\hline \hline 01 & 2756 & 20 & $\mathrm{R} \$$ & $113.638,52$ & 7993 & -5940 & 20745 \\
02 & 10347 & 37 & $\mathrm{R} \$$ & $500.713,77$ & 24690 & -8981 & 43412 \\
03 & 4107 & 29 & $\mathrm{R} \$$ & $232.062,24$ & 9391 & -5475 & 33246 \\
04 & 16966 & 56 & $\mathrm{R} \$$ & $1.008 .498,48$ & 46789 & -13999 & 135203 \\
05 & 11195 & 88 & $\mathrm{R} \$$ & $1.396 .926,85$ & 31780 & -13476 & 110206 \\
06 & 67812 & 819 & $\mathrm{R} \$$ & $13.281 .954,79$ & 197759 & -57543 & 567153 \\
07 & 12420 & 36 & $\mathrm{R} \$$ & $502.924,84$ & 35724 & -8701 & 81013 \\
08 & 3544 & 35 & $\mathrm{R} \$$ & $184.972,40$ & 8548 & -4632 & 34792 \\
09 & 31130 & 140 & $\mathrm{R} \$$ & $2.542 .967,96$ & 84975 & -21066 & 244753 \\
10 & 5808 & 39 & $\mathrm{R} \$$ & $577.486,81$ & 13733 & -2226 & 49078 \\
11 & 16536 & 116 & $\mathrm{R} \$$ & $1.073 .168,17$ & 47682 & -16864 & 135157 \\
12 & 11570 & 46 & $\mathrm{R} \$$ & $725.647,17$ & 21215 & -14318 & 105420 \\
13 & 7965 & 31 & $\mathrm{R} \$$ & $238.163,59$ & 21215 & -8861 & 67100 \\
14 & 6820 & 31 & $\mathrm{R} \$$ & $425.063,79$ & 19522 & -6264 & 62904 \\
15 & 5830 & 29 & $\mathrm{R} \$$ & $751.198,22$ & 16475 & -5525 & 65526 \\
16 & 7367 & 24 & $\mathrm{R} \$$ & $327.408,70$ & 21635 & -7958 & 43060 \\
17 & 6016 & 45 & $\mathrm{R} \$$ & $329.563,65$ & 14009 & -6501 & 51312 \\
18 & 9580 & 50 & $\mathrm{R} \$$ & $740.883,04$ & 28167 & -7778 & 67181 \\
19 & 20255 & 80 & $\mathrm{R} \$$ & $1.710 .040,13$ & 51715 & -11847 & 167360 \\
20 & 14290 & 88 & $\mathrm{R} \$$ & $1.610 .714,27$ & 39637 & -10144 & 174572 \\
\hline Fonte: Adaptado pelo autor dos relatórios de Produção Hemoprod 2012 e custos 2012 da Fundação Hemominas.
\end{tabular}


Tabela 2 - Consolidado Financeiro por Unidades da Fundação Hemominas

\begin{tabular}{|c|c|c|c|c|c|c|c|c|}
\hline DMU & & $\begin{array}{l}p \\
\text { al/ no de }\end{array}$ & & $\begin{array}{l}\text { (I) despesas } \\
\text { ot - desp }\end{array}$ & & $\begin{array}{l}\text { (0) Receita } \\
\text { arrecadada }\end{array}$ & & $\begin{array}{l}\text { (0)desp orç } \\
\text { executada }\end{array}$ \\
\hline 01 & $\mathrm{R} \$$ & $26.642,27$ & $\mathrm{R} \$$ & $369.608,24$ & $\mathrm{R} \$$ & $498.162,32$ & $\mathrm{R} \$$ & $56.202,58$ \\
\hline 02 & $\mathrm{R} \$$ & 47,67 & $\mathrm{R} \$$ & $921.663,74$ & $\mathrm{R} \$$ & 1.491.105,25 & $\mathrm{R} \$$ & $70.884,04$ \\
\hline 03 & $\mathrm{R} \$$ & $34.313,82$ & $\mathrm{R} \$$ & $532.166,12$ & $\mathrm{R} \$$ & $612.837,72$ & $\mathrm{R} \$$ & $75.286,89$ \\
\hline 04 & $\mathrm{R} \$$ & $38.786,18$ & $\mathrm{R} \$$ & $1.903 .865,23$ & $\mathrm{R} \$$ & $3.244 .711,36$ & $\mathrm{R} \$$ & $191.643,62$ \\
\hline 05 & $\mathrm{R} \$$ & $41.107,37$ & $\mathrm{R} \$$ & 2.924.119,06 & $\mathrm{R} \$$ & $2.485 .699,84$ & $\mathrm{R} \$$ & 700,25 \\
\hline 06 & $\mathrm{R} \$$ & 65,44 & $\mathrm{R} \$$ & $17.624 .266,63$ & $\mathrm{R} \$$ & 18.032.725,35 & $\mathrm{R} \$$ & 578,32 \\
\hline 07 & $\mathrm{R} \$$ & $36.709,85$ & $\mathrm{R} \$$ & $1.059 .251,23$ & $\mathrm{R} \$$ & 1.832.928,32 & $\mathrm{R} \$$ & 80,38 \\
\hline 08 & $\mathrm{R} \$$ & $32.803,00$ & $\mathrm{R} \$$ & $580.835,48$ & $\mathrm{R} \$$ & $638.581,46$ & $\mathrm{R} \$$ & $53.916,23$ \\
\hline 09 & $\mathrm{R} \$$ & $52.184,16$ & $\mathrm{R} \$$ & 4.223.162,47 & $\mathrm{R} \$$ & $6.687 .242,10$ & $\mathrm{R} \$$ & $404.350,26$ \\
\hline 10 & $\mathrm{R} \$$ & $38.304,35$ & $\mathrm{R} \$$ & $1.192 .886,46$ & $\mathrm{R} \$$ & 1.054 .3 & $\mathrm{R} \$$ & 83,10 \\
\hline 11 & $\mathrm{R} \$$ & $50.046,29$ & $\mathrm{R} \$$ & 2.523.738, & $\mathrm{R} \$$ & 3.034 .8 & $\mathrm{R} \$$ & $382.872,85$ \\
\hline 12 & $\mathrm{R} \$$ & $31.233,87$ & $\mathrm{R} \$$ & $1.369 .421,00$ & $\mathrm{R} \$$ & $2.577 .574,75$ & $\mathrm{R} \$$ & $196.672,63$ \\
\hline 13 & $\mathrm{R} \$$ & $30.672,15$ & $\mathrm{R} \$$ & $530.900,48$ & $\mathrm{R} \$$ & $1.473 .200,96$ & $\mathrm{R} \$$ & 027,73 \\
\hline 14 & $\mathrm{R} \$$ & $34.927,51$ & $\mathrm{R} \$$ & $844.020,49$ & $\mathrm{R} \$$ & $1.450 .906,16$ & $\mathrm{R} \$$ & 989,66 \\
\hline 15 & $\mathrm{R} \$$ & $33.323,08$ & $\mathrm{R} \$$ & $1.034 .491,90$ & $\mathrm{R} \$$ & $1.162 .498,09$ & $\mathrm{R} \$$ & $47.268,07$ \\
\hline 16 & $\mathrm{R} \$$ & $24.944,12$ & $\mathrm{R} \$$ & $800.110,32$ & $\mathrm{R} \$$ & $1.546 .060,63$ & $\mathrm{R} \$$ & $46.186,04$ \\
\hline 17 & $\mathrm{R} \$$ & $32.309,93$ & $\mathrm{R} \$$ & $606.835,16$ & $\mathrm{R} \$$ & $1.075 .109,12$ & $\mathrm{R} \$$ & $47.646,44$ \\
\hline 18 & $\mathrm{R} \$$ & $31.984,40$ & $\mathrm{R} \$$ & $1.330 .523,25$ & $R \$$ & $1.740 .963,57$ & $\mathrm{R} \$$ & $121.870,72$ \\
\hline 19 & $\mathrm{R} \$$ & $35.224,41$ & $\mathrm{R} \$$ & $3.243 .885,84$ & $\mathrm{R} \$$ & $3.910 .179,50$ & $\mathrm{R} \$$ & $202.504,68$ \\
\hline 20 & $\mathrm{R} \$$ & $40.360,98$ & $\mathrm{R} \$$ & 2.964.706,09 & $\mathrm{R} \$$ & 3.324.899,55 & $\mathrm{R} \$$ & $266.091,84$ \\
\hline
\end{tabular}

Importante relatar que a variável "total de hemocomponentes descartados" será computada com valores negativos, pois o objetivo é a minimização desta variável no contexto operacional e produtivo.

Um terceiro modelo DEA denominado modelo de medidas especificas-MME com retorno constante de escala CCR-NCN-O-C foi utilizado nas variáveis operacionais e financeiras, a fim de obter informações mais detalhadas.

Por fim, um mix de variáveis financeiras e operacionais foi analisado dentro dos escopos BCC-I e BCC-O. As variáveis analisadas neste contexto com seus dados coletados e tabulados por DMUs estão na Tabela 3. 
Tabela 3. Consolidado Financeiro e Operacional por Unidades da Fundação Hemominas

\begin{tabular}{|c|c|c|c|c|c|c|c|c|c|}
\hline \multirow{2}{*}{$\begin{array}{c}\text { DMU } \\
01\end{array}$} & \multicolumn{2}{|c|}{$\begin{array}{l}\text { (I) desp pessoal/ } \\
\text { no de funcionarios }\end{array}$} & \multicolumn{2}{|r|}{$\begin{array}{l}\text { (I)desp orç } \\
\text { fixada }\end{array}$} & \multicolumn{2}{|c|}{$\begin{array}{l}\text { (I) desp totalizadas } \\
\text { - desp pessoal }\end{array}$} & \multirow{2}{*}{$\begin{array}{c}\begin{array}{c}\text { (O)Tot } \\
\text { hemoc } \\
\text { prod }\end{array} \\
7993\end{array}$} & \multirow{2}{*}{$\begin{array}{c}\begin{array}{c}\text { (O)Tot } \\
\text { hemoc } \\
\text { Jescart }\end{array} \\
-5940\end{array}$} & \multirow{2}{*}{$\begin{array}{l}\begin{array}{l}\text { (0) serv } \\
\text { clínicos } \\
\text { efetuad }\end{array} \\
20745\end{array}$} \\
\hline & $\mathrm{R} \$$ & $26.642,27$ & $\mathrm{R} \$$ & $47.335,93$ & $\mathrm{R} \$$ & 369.608,24 & & & \\
\hline$\hat{02}$ & $\mathrm{R} \$$ & $32.147,67$ & $\mathrm{R} \$$ & $83.110,34$ & $\mathrm{R} \$$ & $921.663,74$ & 24690 & -8981 & 43412 \\
\hline 03 & $R \$$ & $34.313,82$ & $R \$$ & $61.783,09$ & $\mathrm{R} \$$ & $532.166,12$ & 9391 & -5475 & 33246 \\
\hline 04 & $R \$$ & $38.786,18$ & $\mathrm{R} \$$ & $193.525,40$ & $\mathrm{R} \$$ & $1.903 .865,23$ & 46789 & -13999 & 135203 \\
\hline 05 & $\mathrm{R} \$$ & $41.107,37$ & $\mathrm{R} \$$ & $427.445,25$ & & & 31780 & -13476 & 110206 \\
\hline 06 & $\mathrm{R} \$$ & & $\mathrm{R} \$$ & 1.062 .6 & & 17.6 & 197759 & -57543 & \\
\hline 07 & $\mathrm{R} \$$ & & $\mathrm{R} \$$ & & $\mathrm{R} \$$ & & 35724 & -8701 & \\
\hline 08 & $\mathrm{R} \$$ & & $\mathrm{R} \$$ & & & & 8548 & -4632 & \\
\hline 09 & $\mathrm{R} \$$ & & $\mathrm{R} \$$ & & & & 84975 & -21066 & 753 \\
\hline 10 & $\mathrm{R} \$$ & & $\mathrm{R} \$$ & & & & 13733 & -2226 & 49078 \\
\hline 11 & $\mathrm{R} \$$ & & $\mathrm{R} \$$ & & & & 47682 & -16864 & 135157 \\
\hline 12 & $\mathrm{R} \$$ & & $\mathrm{R} \$$ & & & & 21215 & -14318 & 105420 \\
\hline 13 & $\mathrm{R}$ & 30. & $\mathrm{R} \$$ & & $\mathrm{R}$ & & 21215 & -8861 & 67100 \\
\hline 14 & $\mathrm{R} \$$ & 34. & $\mathrm{R} \$$ & & & & 19522 & -6264 & 62904 \\
\hline 15 & $\mathrm{R} \$$ & & $\mathrm{R} \$$ & & $\mathrm{R}$ & & 16475 & -5525 & 65526 \\
\hline 16 & $\mathrm{R} \$$ & & $\mathrm{R} \$$ & & $\mathrm{R}$ & & 21635 & -7958 & 43060 \\
\hline 17 & $\mathrm{R} \$$ & 32.3 & $\mathrm{R} \$$ & 0,46 & $\mathrm{R} \$$ & & 14009 & -6501 & 51312 \\
\hline 18 & $\mathrm{R} \$$ & 31.9 & $R \$$ & 125.2 & $\mathrm{R} \$$ & 1.33 & 28167 & -7778 & 67181 \\
\hline 19 & $\mathrm{R} \$$ & $35.224,41$ & $\mathrm{R} \$$ & 239.1 & $\mathrm{R} \$$ & & 51715 & -11847 & 167360 \\
\hline 20 & $\mathrm{R} \$$ & 40.360 .98 & $\mathrm{R} \$$ & 289.620 .96 & $\mathrm{R} \$$ & 2.964 .706 .09 & 39637 & -10144 & 174572 \\
\hline
\end{tabular}

\section{Análise dos resultados}

\subsection{Modelo Operacional em BCC-I e BCC-O}

Os dados operacionais e financeiros foram processados no software DEA-solver disponível no site www.saitech-inc.com, sendo os resultados apresentados e analisados com base no escopo de construção dos modelos. O modelo BCC de retornos variáveis a escala foi utilizado, considerando-se os complementos I e O, respectivamente, com orientações a insumos (inputs) ou produto (outputs).

No contexto de minimização do insumo modelo BCC-I, premissa ideal no escopo das organizações públicas, ficou evidenciado apenas 4 DMU's fora da fronteira de eficiência, na sequência, DMU's 05, 03, 17 e 02 sendo que, a DMU 02 está ineficiente decrescente e as demais $(05,03$ e 17) ineficientes com retorno constante conforme demonstrado na Tabela 4.

O rendimento ineficiente decrescente, DMU 02, demonstra a necessidade de correção de dois problemas, a variação dos Produtos em excesso e a subutilização dos Insumos considerados.

Verificou-se ainda que, das 20 DMU's analisadas, 14 apresentaram rendimento constante de escala e eficiência técnica, melhor situação, onde a DMU utiliza os recursos sem desperdícios operando em escala ótima, conforme Tabela 4. 
Ficou evidenciado também que 2 DMU's, a saber, DMU's 09 e 11 embora estejam na fronteira de eficiência estão em posição decrescente, ou seja, embora tecnicamente eficientes operam acima da escala ótima.

Para o rendimento decrescente eficiente, situação das DMU's 09 e 11, temos um volume de Produtos acima da escala ótima, situação que pode ser mais bem trabalhada com vistas à minimização do custo levando-se em consideração as relações entre as quantidades de Insumos e Produtos.

No modelo BCC-O com vistas a maximização dos Produtos dada a mesma quantidade de Insumos, ficou evidenciado as mesmas DMU's eficientes, 16 (dezesseis) no total e as mesmas ineficientes do modelo BCC-I (DMU's 05, 17, 03 e 02), conforme Tabela 4.

No comparativo entre os modelos Tabela 9, houve apenas pequenas variações nos escores das DMU's analisadas e dois reposicionamentos de ranking, DMU's 03 e 17 em relação ao escore analisado. As projeções virtuais baseadas nas variáveis determinadas foram calculadas e discriminadas no Anexo A, bem como a fronteira de possibilidades está disposta no Anexo D.

\subsection{Modelo Operacional em CCR-NCN-O-C}

O modelo considera como constante a escala de retorno, ou seja, o aumento proporcional dos Insumos (I) conduz a um aumento na mesma proporção de Produtos (O) com uma variação constante.

Foi considerada também a incapacidade de controle dos tomadores de decisão de determinada variável, denominada não discricionária ou exógena, a fim de avaliar dentro de parâmetros mais restritos a eficiência dos conjuntos das DMU's consideradas.

A variável selecionada foi a "total de hemocomponentes descartados" devido a dificuldade de controle tanto no processo produtivo (rompimento de bolsa, validade, outros) além de métodos de acondicionamento por parte dos hospitais e clinicas não conformes, embora, este processo esteja normatizado e determinado na RDC 57.

O modelo segue a denominação CCR-NCN-O-C tendo os Produtos subdivididos em variáveis discricionários (D) e não discricionários (ND) a variável selecionada passa a ser denominada "total de hemocomponentes descartados (ON)".

Das 20 DMU's analisadas, 12 estão na fronteira de eficiência e 8 fora da fronteira (tabela 05). Este modelo demonstrou que algumas DMU's eficientes nos modelos BCC-I e BCC-O são falsos eficientes quando analisadas em retorno constante delimitando uma variável de difícil controle.

As DMU's 09, 10, 11 e 19 são falsos eficientes, pois os escores obtidos no retorno variável diferem do retorno constante $(\theta B C C \neq \theta C C R)$. Esta diferença demonstra uma ineficiência produtiva, operacional e de escala de produção.

\subsection{Modelo Financeiro em BCC-I e BCC-O}


No modelo BCC-I, ficou evidenciado 6 DMU's que estão na fronteira de eficiência, sendo que 4 são eficientes em escala e tecnicamente duas DMU's, 01 e 16, estão com retorno crescente e tecnicamente eficiente, 12 DMU's estão fora da fronteira de eficiência com retorno crescente. Encontraram-se, ainda, duas DMU's 04 e 11 que também estão fora da fronteira de eficiência, ou seja, em condição ineficiente, mas com retorno constante (Tabela 05).

Para o retorno crescente eficiente, temos que as DMU's 01 e 16 estão com volume de Produtos abaixo do esperado, o aumento de Produtos deve ocorrer com incorporação de Insumos e Produtos com equiproporcionalidade. Neste caso, o objetivo é a minimização das despesas e a otimização das receitas e do orçamento, para que as DMU's atinjam a fronteira de eficiência.

Para as 12 DMU's com ineficiência técnica e retorno crescente, temos que estas utilizam os Insumos em excesso, no caso representado pelas variáveis de despesas. Em contrapartida, estão com os Produtos abaixo representados pelas variáveis receitas e orçamentos. Devem-se eliminar os excessos de Insumos e aumentar os Produtos via introdução reduzida e controlada dos Insumos considerados.

Já as DMU's 04 e 11 ineficientes com retorno constante, a postura consiste em reduzir o excesso de Insumos bem como buscar melhorar os fatores de produção representados pelos Produtos com vias a otimizar o uso dos Insumos.

No modelo BCC-O, constatou-se 6 DMU's na fronteira de eficiência, a saber, DMU 01, 06, 09, 12, 13 e 16, sendo que, destas, apenas 4 DMU's (06, 09, 12 e 13) são eficientes tecnicamente e em escala conforme tabela 05.

Houve também 14 DMU's ineficientes tecnicamente, destas, 12 DMU's estão em retornos constantes e apenas uma DMU (03) em retorno crescente.

No comparativo entre os modelos BCC-I e BCC-O, houve diferenças de posicionamento no ranking para as DMU's ineficientes, as variações mais significativas foram detectadas nas DMU's 08, 10, 15 e 17.

A postura destas DMU's $(08,10,15$ e 17) denota que utilizam dispendiosamente os insumos e os fatores de produção são mal geridos, pois também não há maximização dos resultados conforme demonstrado na variação BCC-O.

Foram encontradas DMU's em situação de ineficiência técnica com retorno crescente, nos dois modelos analisados (BCC-Ie O), DMU's ineficientes com retorno constante e DMU's eficientes com retorno crescente.

$\mathrm{Na}$ postura de ineficiência técnica com retorno crescente, temos dois problemas, o excesso de uso dos Insumos e a baixa variação do uso dos Produtos, a eliminação dos excessos em relação aos Insumos é importante e sua ação conduz a eficiência técnica. Quanto aos Produtos, devem ser maximizados por meio do uso equacionado e pontual dos Insumos. Temos, portanto, DMU's que utilizam dispendiosamente os insumos, gastos gerais e despesa com pessoal e ainda não maximizam a receita e o uso do orçamento.

Situação pouco diferente está as DMU's ineficientes com retorno constante, esta postura, embora estejam em escala ótima, denota a necessidade de redução dos Insumos mantendo constante os Produtos. Aqui, temos DMU's que até maximizam a receita e o orçamento realizado, no entanto, não promovem a redução das despesas analisadas.

Já para as eficientes com retorno crescente, ocorre a baixa variação do uso dos Produtos, isto significa que as DMU's podem aumentar a utilização dos Produtos a custos 
decrescentes, ou seja, buscar o uso racional, pontual e objetivo dos Insumos. Neste aspecto, as DMU's poderiam maximizar o uso da receita e a execução do orçamento realinhando e detectando pontos desnecessários e dispendiosos em relação aos insumos, gastos gerais e despesa com pessoal. As projeções virtuais baseadas nas variáveis determinadas foram calculadas e discriminadas no Anexo $\mathrm{B}$, bem como a fronteira de possibilidades está disposta no Anexo D.

\subsection{Modelo Financeiro em CCR-NCN-O-C}

A variável selecionada foi a "Receita arrecadada" dada a dificuldade de controle, por estar diretamente relacionada à demanda pelos hemocomponentes e serviços prestados via SUS e privado aos hospitais, prefeituras e governo federal.

Aplicamos o modelo financeiro constante na tabela 02 na análise CCR-NCN-O-C do software DEA - Solver e, Dadas as premissas do modelo ficou evidenciado apenas 4 DMU's na fronteira de eficiência, a saber, 13,12,09 e 06 o restante, 16 DMU's, estavam fora da fronteira de eficiência conforme demonstrado na tabela 04.

O modelo confirma 2 DMU's falso eficientes, DMU's 01 e 16, os escores obtidos no retorno variável diferem do retorno constante $(\theta B C C \neq \theta C C R)$ esta diferença demonstra uma ineficiência produtiva, operacional e de escala de produção.

\subsection{Modelo Financeiro em BCC-I e BCC-O}

O modelo utilizou-se das variáveis constantes na tabela 03 , tendo como objetivo verificar o grau de performance das DMUs dados os Insumos e Produtos em análise.

O resultado no modelo BCC-I indicou 15 DMU's na fronteira de eficiência, a saber, DMU's $01,04,06,07,08,09,10,12,13,14,15,16,17,19$ e 20 sendo que, 5 DMU's 01, 08, 14,16 e 17 estão eficientes com retorno crescente, as demais são eficientes com retorno constante. As 05 DMU's restantes, DMU's 02, 03, 05 e 18 estão ineficientes tecnicamente com retorno crescente.

O detalhe fica nas 5 DMU's eficientes com retorno crescente, embora estejam na fronteira de eficiência e não há excesso de Insumos. No entanto, estão com o volume de Produtos abaixo do ideal, provavelmente porque estão utilizando os fatores de produção inadequadamente neste contexto.

As DMU's restantes estão com dois problemas, o excesso de Insumos e possivelmente a baixa produção, o primeiro problema pode ser compensado através do uso equacionado dos recursos disponibilizados, o segundo problema pode ser compensado por meio da sistematização e parametrização dos processos produtivos. 
O modelo BCC-O obteve 13 DMU's na fronteira de eficiência, sendo que 10 DMU's 04, $06,07,09,10,12,13,15,19$ e 20 são eficientes técnica e escalarmente as outras 3 DMU's 01,14 e 16 são eficientes com retorno crescente. Ficou evidenciado também 7 DMU's fora da fronteira de eficiência, sendo que, 5 DMU's 03, 05, 08, 11 e 17 são ineficientes com retorno constante, as DMU's 02 e 18 são ineficientes com retorno crescente.

$\mathrm{Na}$ análise do comparativo entre os modelos BCC-I e BCC-O houve reposicionamentos de ranking entre as DMU's, a observação mais importante ficou com o posicionamento das DMU's 08 e 17 as quais eram eficientes no modelo BCC-I, passaram a ineficientes no modelo $\mathrm{BCC}-\mathrm{O}$. As projeções virtuais baseadas nas variáveis determinadas foram calculadas e discriminadas no Anexo $\mathrm{C}$, bem como a fronteira de possibilidades está disposta no Anexo D. 
Tabela 4. Comparativo no ranking de eficiência mod. BCC-I, BCC-O e CCR-NCN-O-C nos escopos considerados

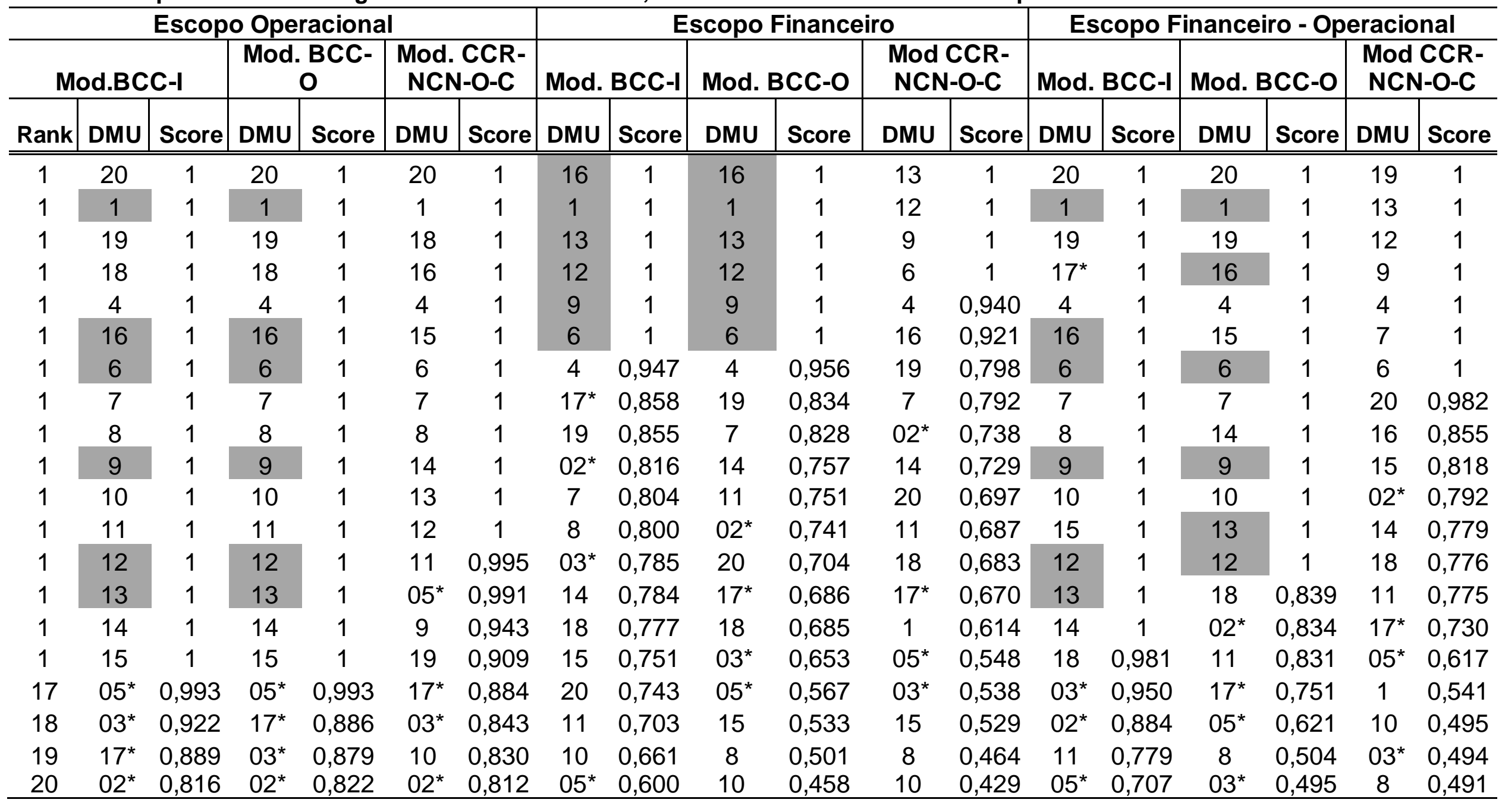


Tabela 5. Comparativo da situação das DMU's quanto à eficiência técnica e o tipo de retorno

\begin{tabular}{|c|c|c|c|c|c|c|c|c|c|c|c|c|c|c|c|c|c|c|}
\hline \multicolumn{7}{|c|}{ Escopo Operacional } & \multicolumn{6}{|c|}{ Escopo Financeiro } & \multicolumn{6}{|c|}{ Escopo Financeiro Operacional } \\
\hline \multicolumn{4}{|c|}{ Modelo BCC-I } & \multicolumn{3}{|c|}{ Modelo BCC-O } & \multicolumn{3}{|c|}{ Modelo BCC-I } & \multirow[b]{2}{*}{ Score } & \multirow[b]{2}{*}{ RTS } & \multirow[b]{2}{*}{ Proj } & \multirow[b]{2}{*}{ Score } & \multirow[b]{2}{*}{ RTS } & \multirow[b]{2}{*}{ Proj } & \multirow[b]{2}{*}{ Score } & \multirow[b]{2}{*}{ RTS } & \multirow[b]{2}{*}{ Proj } \\
\hline DMU & Score & RTS & Proj & Score & RTS & Proj & Score & RTS & Proj & & & & & & & & & \\
\hline $\begin{array}{l}01 \\
02\end{array}$ & $\begin{array}{c}1 \\
0,816\end{array}$ & $\mathrm{C}$ & D & $\begin{array}{c}1 \\
0,822\end{array}$ & $\mathrm{C}$ & D & $\begin{array}{c}1 \\
0,816\end{array}$ & 1 & 1 & $\begin{array}{c}1 \\
0,742\end{array}$ & 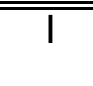 & C & $\begin{array}{c}1 \\
0,884\end{array}$ & 1 & 1 & $\begin{array}{c}1 \\
0,834\end{array}$ & 1 & 1 \\
\hline 03 & 0,922 & & C & 0,879 & & $\mathrm{C}$ & 0,785 & & I & 0,653 & & I & 0,950 & & i & 0,495 & & C \\
\hline 04 & 1 & C & & 1 & C & & 0,947 & & C & 0,956 & & C & 1 & C & & 1 & C & \\
\hline 05 & 0,993 & & C & 0,993 & & C & 0,6 & & I & 0,568 & & C & 0,707 & & 1 & 0,621 & & C \\
\hline 06 & 1 & C & & 1 & C & & 1 & C & & 1 & C & & 1 & C & & 1 & C & \\
\hline 07 & 1 & C & & 1 & C & & 0,805 & & 1 & 0,829 & & C & 1 & C & & 1 & C & \\
\hline 08 & 1 & C & & 1 & C & & 0,801 & & I & 0,502 & & I & 1 & I & & 0,504 & & C \\
\hline 09 & 1 & D & & 1 & D & & 1 & C & & 1 & C & & 1 & C & & 1 & C & \\
\hline 10 & 1 & C & & 1 & C & & 0,662 & & 1 & 0,459 & & C & 1 & C & & 1 & C & \\
\hline 11 & 1 & D & & 1 & D & & 0,704 & & C & 0,751 & & $\mathrm{C}$ & 0,779 & & I & 0,831 & & C \\
\hline 12 & 1 & C & & 1 & C & & 1 & C & & 1 & C & & 1 & C & & 1 & C & \\
\hline 13 & 1 & C & & 1 & C & & 1 & C & & 1 & C & & 1 & C & & 1 & C & \\
\hline 14 & 1 & C & & 1 & C & & 0,785 & & 1 & 0,758 & & C & 1 & I & & 1 & I & \\
\hline 15 & 1 & C & & 1 & C & & 0,751 & & I & 0,533 & & C & 1 & C & & 1 & C & \\
\hline 16 & 1 & C & & 1 & C & & 1 & 1 & & 1 & 1 & & 1 & I & & 1 & I & \\
\hline 17 & 0,889 & & C & 0,886 & & C & 0,858 & & 1 & 0,686 & & C & 1 & I & & 0,751 & & C \\
\hline 18 & 1 & C & & 1 & C & & 0,778 & & 1 & 0,685 & & C & 0,981 & & 1 & 0,839 & & 1 \\
\hline 19 & 1 & C & & 1 & C & & 0,856 & & 1 & 0,835 & & C & 1 & C & & 1 & C & \\
\hline 20 & 1 & C & & 1 & C & & 0,743 & & 1 & 0,705 & & C & 1 & C & & 1 & C & \\
\hline
\end{tabular}


Foram encontradas algumas DMU's eficientes, a saber, DMU's 01, 06, 09, 12, 13 e 16, demarcadas na tabela 29 nos escopos Operacional, Financeiro e Financeiro Operacional considerados (BCC-I e BCC-O).

Não obstante, apenas 3 (três) DMU's podem ser consideradas MPSS- Mostproductive scale size, ou seja, são eficientes tecnicamente e em escala, demonstrando eficiência operacional e financeira tanto no modelo variável (BCC-I e BCC-O) voltado aos Insumos quanto no modelo voltado aos Produtos bem como no modelo constante (CCR), a saber, DMU's 06, 12 e 13 demarcadas na tabela 05.

Foram encontradas 4 (quatro) DMU's ineficientes tecnicamente e em escala no escopo Operacional (BCC-I, BCC-O e CCR-NCN-O-C), Financeiro (BCC-I, BCC-O e CCR-NCN-O-C) e escopo financeiro-operacional (BCC-I e BCC-O e CCR-NCN-O-C), sendo elas as DMU's 03, 05, 11 e 17, demarcadas na Tabela 5. A DMU 17 aparece eficiente no escopo FinanceiroOperacional (BCC-I), entretanto, sua postura é de ineficiência corroborada pela score $<1$ do modelo CCR-NCN-O-C do escopo considerado.

Neste aspecto, importante ressaltar que a DMU 08 foi eficiente apenas no escopo Operacional, embora tenha ocorrido eficiência no escopo Financeiro-Operacional modelo BCC-I sua posição é de ineficiência de escala corroborada pelo score CCR menor que o score BCC. A situação operativa desta DMU deve ser mais bem analisada dentro do contexto considerado.

$\mathrm{Na}$ posição de minimização dos insumos, bem como no de maximização dos produtos, o destaque ficou para as DMU's 07, 10, 15, 19 e 20 ineficientes com retorno crescente no escopo financeiro modelo BCC-I, passam a tornam-se eficientes no escopo financeiro-operacional modelos BCC-I e BCC-O, o que denota, por meio das variáveis analisadas e no modelo considerado, que estas DMU's utilizam os Insumos e Produtos mais eficientemente, conduzindo-as à fronteira de eficiência.

Entretanto, levando-se em consideração o contexto das inversões financeiras caracterizadas em despesas e seus resultados caracterizados em produtos/serviços ofertados, temos que as unidades realmente eficientes neste espectro são as DMU's 07 e 19.

\subsection{Análise de Correlação entre Modelo de Eficiência de Produção e}

\section{Financeiro}

O grau de correlação entre os modelos de eficiência de produção e financeiro, tabela 06 , foram compilados e rodados no software $R$ com os resultados descritos a seguir.

O Gráfico 1, demonstra o grau de correlação de Pearson baseado nos valores da tabela 31, o resultado delineia uma correlação entre o escopo de produção e financeiro no modelo BCC-I no valor de: corr(Producao_BCC-I, Financeiro_BCC-I) =0,084. Uma reta paralela ao eixo das ordenadas indica fraca correlação, devido a não formação de um eixo que caracteriza o relacionamento entre as variáveis. Tal resultado é corroborado com o baixo índice de correlação estimado entre as variáveis analisadas.

Temos que, o resultado demonstra uma correlação entre o escopo de produção e financeiro no modelo BCC-O no valor de: corr(Producao_BCC-O, Financeiro_BCC-O) = 0,194. O resultado do Gráfico 2 segue praticamente o mesmo parâmetro do Gráfico 1 com 
fraca correlação corroborado com o baixo índice de correlação calculado entre as variáveis analisadas.

\section{Considerações Finais}

Os resultados finais demonstram que existe uma fraca correlação estatística entre eficiência operacional e eficiência financeira, tanto no modelo BCC-I quanto no modelo BCCO conforme análise delineada anteriormente. Muito embora algumas DMU's tenham apresentado eficiência Operacional, Financeira e Financeira-Operacional, tal resultado não é a regra, não se encontrando assim evidências para rejeitar a hipótese de correlação nula entre eficiência operacional e eficiência financeira. Assim, a hipótese procurada pela pesquisa, de correlação positiva entre eficiência operacional e eficiência financeira não foi corroborada.

No escopo operacional, ficou claro o grau de eficiência das DMU's analisadas, demonstrando o elevado grau de eficiência técnica e em escala com baixa variação entre as DMU's ineficientes. Este posicionamento pode ser explicado dado o elevado grau técnico no processo produtivo, embasados nos mecanismos de controle, acondicionamento, análise e distribuição preconizados na Portaria 1353, RDC 57 e órgãos regulatório governamentais.

No escopo financeiro o cenário é pouco homogêneo, com elevado número de DMU's fora da fronteira de eficiência, e variação considerável entre estas $(0,6$ a 0,94-BCC-l e 0,45 a 0,95-BCC-O). Neste escopo, tem-se um cenário singular, no sentido de que as despesas e os gastos com pessoal precisam ser mais bem equacionados, de maneira a promover as melhorias e condições necessárias ao bom desempenho das DMU's analisadas. Adicionalmente, as receitas arrecadas e o orçamento executado devem ser otimizados, levando-se em consideração até melhorias tecnológicas nos processos laborais e de gestão.

No escopo financeiro-operacional, percebe-se o grau de ineficiência da maioria das DMU's analisadas, a condição de falso eficiente fica bem caracterizada no modelo CCR-NCN$\mathrm{O}-\mathrm{C}$ do escopo analisado. O uso do dos recursos caracterizados em despesas e seus resultados em produtos e serviços ofertados precisa de uma avaliação mais minuciosa. Provavelmente o impacto nos resultados é decorrente do processo de gestão e do processo produtivo. Deve-se ressaltar que a definição desse escopo auxilia na legitimidade da análise do escopo financeiro.

Para o modelo CCR-NCN-O-C percebe-se o aumento de DMU's ineficientes no escopo operacional e financeiro, corroborando com a proposição de Banker e Morey (1986) ao não permitir que as DMU's controlem estas variáveis para se tornarem eficientes. Nesse modelo, algumas DMU's assumem condição de falso eficientes, situação que ocorreu com as DMU's 09, 11, 19 e 10 no escopo Operacional, DMU's 01 e 16 no escopo Financeiro e DMU's 01, 10, 14, 15, 16 e 20 no escopo Financeiro-Operacional. Essas DMU's, embora apresentem eficiência, em algum modelo (BCC-I ou BBC-O), estão em ineficiência de escala, pois seu score CCR e menor que o score BCC.

Algumas limitações e possibilidades do estudo devem ser consideradas. No contexto operacional, outras variáveis como índice de eficácia transfusional, o total enviado para 
produção de hemoderivados e o número de reações transfusionais não foram analisadas e podem possivelmente interferir na eficiência operacional das DMU's analisadas.

Para o escopo financeiro as variáveis como custo de produção de cada hemocomponente, bem como os gastos por centro de custo de cada DMU não foram analisados. No que tange a primeira variável, esta pode ser agregada para a análise da eficiência econômica e no caso da segunda variável, esta pode interferir no grau de eficiência das DMU's avaliadas.

Outros estudos futuros_podem complementar e consubstanciar a presente análise. Por exemplo, pode-se impor a avaliação das DMU's no contexto da eficiência econômica com vistas e mensurar a eficiência de custo e a eficiência de receita, em um contexto de variação intertemporal. Além disso, no aspecto estratégico, pode-se realizar a avaliação de cada DMU confrontando seus indicadores setoriais com objetivo de mensurar o grau de eficiência de cada centro de custo e efetuar a comparação dos resultados com seus pares homogêneos.

Percebe-se que os modelos DEA são importantes para o entendimento do grau de desempenho das organizações produtivas públicas ou privadas, ao mesmo tempo, 0 instrumento auxilia e fornece subsídios fundamentados aos gestores para avaliarem e se posicionarem frente aos seus pares.

É importante evidenciar que a gestão eficaz do erário é responsabilidade jurídico-legal dos gestores públicos. Portanto, minimizar custos e otimizar recursos disponíveis é condição fundamental e premente para gestores da esfera pública. Gestores devem focar suas estratégias para atender adequadamente agentes externos e os clientes cidadãos. Assim, o conhecimento do grau de eficiência e eficácia das instituições e ou órgãos públicos deve ser fomentado e aprimorado de modo a fazer com que o país trilhe o caminho da justiça social.

\section{Referências Bibliográficas}

Agência Nacional de Vigilância Sanitária. (2010). Resolução RDC no 57, de 16 de dezembro de 2010. Brasília.

Banker, Rajiv D. e cols. (1984). Some Models for estimating technical and scale inefficiencies in Data Envelopment Analysis. Management Science, 30, 9, p. 1078-1092, Sept.

Banker, Rajiv D., \& Morey, Richard C. (1986). Efficiency Analysis for Exogenously Fixed Inputs and Outputs Operations Research, Management Science, vol. 34, n. 4; pp.. 513-521.

Barney, Jay B. (2002) Gaining and Sustaining Competitive Advantage. Upper Saddle River, New jersey: Pearson Education.

Bowlin, William F. (1998). Measuring performance: an introduction to Data Envelopment Analysis. The Journal of Cost Analysis. Disponível em: www.sceaonline.net/Journ_Fall98_BOWLIN.pdf. [Data de acesso: 10 de set. 2012].

Brasil. (1964). Lei no 4.320, de 17 de março de 1964. Brasília.

Brasil. (1990). Lei no 8.080, de 19 de setembro de 1990. Brasília.

Brasil. (2000). Lei complementar no 101, de 4 de maio de 2000. Brasília.

Brasil. (2011). Lei no 12.527, de 18 de novembro de 2011. Brasília. 
Bresser -Pereira, Luiz Carlos. (1998). Gestão do setor público: estratégia e estrutura para um novo Estado. Em Bresser -Pereira, Luiz Carlos., \& Spink, Peter. Reforma do Estado e administração pública gerencial / Org. 2 ed. Rio de Janeiro: Fundação Getulio Vargas.

Carton, Robert B., \& Hofer, Charle W. (2006).Measuring Organizational Performance: metrics for Entrepreneurchip and Strategic Management Research. Edward Elgar Publishing Inc.

Chandler, Gaylen N., \& Hanks, Steven. (1994). H. Market attractiveness, resource-based capabilities, venture strategies and venture performance. Journal of Business Venturing, v.9, n.4, p.331-349.

Charnes, Abraham., Cooper, William W., Lewin, Arie Y., \& Seiford, Lawrence M. (1997). Data Envelopment Analysis: theory, methodology and application. Massachusetts: Kluer.

Cooper, William., Seiford, Lawrence M., \& Tone, Kaoru. (2007). Data Envelopment Analysis: A Comprehensive Text with Models, Applications, References. Second Edition. Springer.

Cooper, William., Seiford, Lawrence M., \& Zhu, Joe. (2004). Handbook of data envelopment analysis: Models and Methods. Ed. Springer.

Farrel, Michael J. (1957). The mensurement of productive efficiency. Journal of the Royal Statistical Society, Series A, part III, p.253-290.

Ferreira, Carlos. M. C., \& Gomes, Adriano. (2009). Introdução à análise envoltória de dados: teoria, modelos, e aplicações. Viçosa, MG: Editora UFV.

Fitzsimmons, James A., \& Fitzsimmons, Mona J. (2000). Administração de serviços: operações estratégicas e tecnologia de informação. Tradução de Service Management: operations, strategy and information technology. 2. ed. Porto Alegre. Bookman.

Fundação Hemominas (2007).1985-2007/ Centro de Hematologia e Hemoterapia do Estado de Minas Gerais - Belo Horizonte: Fundação Hemominas, 2007.

Fundação Hemominas. (2012). Relatório de produção consolidado FH hemoprod. [doc. interno]. Belo Horizonte.

Fundação Hemominas. (2012). Relatório perdas de produção FH. [doc. interno]. Belo Horizonte.

Fundação Hemominas. (2012). Relatório de custos FH. [doc. interno]. Belo Horizonte.

Fundação Hemominas. (2012). Consolidado GMD/Unidades FH. [doc. interno]. Belo Horizonte.

Hao, Steven., \& Wallace, Edwaurd. (1992). Using Data Envelopment Analysis and translog methods to investigate blood center operations: efficiency, economies of scale, and economies of scope.

ludicibus, Sérgio., \& Marion, José C. (2002). Introdução à Teoria da Contabilidade: Para o nível de graduação. 2. ed. São Paulo: Atlas.

Kettl, Donald. (1996). The global revolution. Reforming government sector management in: Seminário Internacional A Reforma do Estado na América Latina e no Caribe. Brasília, Ministério da Administração Federal e Reforma do Estado (Maré), BID, Brasilia,.16-17 de maio.

Laupacis, Andreas. e cols.. (1996). Cost of Allogeneic and Autologous Blood Transfusion in Canadá. Can Med. Association JOurnal. May.

Marketta, Veihola., Aroviita Pekka., Kekomäki Riita., Miika Linna., \& Sintonen, Harri.. (2008). Discarded cellular components and the technical efficiency of component preparation, The European Journal Health Economics, v. 9, n.4,p. 325.

Marketta, Veihola., Aroviita Pekka., Kekomäki Riita., \& Sintonen, Harri.. (2008). Working hours and produced cellular components as variables to evaluate blood bank efficiency, Transfusion Medicine, v. 18, n.4.

Marketta, Veihola., Aroviita Pekka., Kekomäki Riita., Miika Linna., \& Sintonen, Harri.. (2006). International comparison of the technical efficiency of component preparation. Transfusion. Dec ;v.46, n.12, p.2109-211.

Minas Gerais. (1989). Lei no 10057, de 26 de dezembro de 1989. Assembléia legislativa de Minas Gerais. Diário do Executivo. 27/12/1989. p. 2_col1 
Ministério da Saúde. (2011). Portaria № 1.353, de 13 de Junho de 2011. Brasília.

Ozcan, Yasar. A. (2008). Health Care Benchmarking and Performance Evaluation- Na Assessment using Data Envelopment Analysis (DEA). Springer.

Paiva, Francisco Canindé de. (2000). Eficiência produtiva de programas de ensino depôs graduação em engenharias: uma aplicação do método Análise Envoltória de Dados DEA. Dissertação. UFV.

Peña. Carlos. 2008). A modelo f Evaluation of the efficiency of the Public Sector through the Method Data Envelopment Analysis (DEA). RAC, Curitiba, v.12, n.1, p.83-106, 2008.

Pereira, Arturo. (2006). Economies of scale in blood banking: a study based on data envelopment analysis. Vox Sanguinis. v..90, n.4, p.308, 2006.

Pitocco, Cheistine \& Sexton, Thomas. (2005). Alleviating blood shortages in a resourceconstrained environment. Transfusion, v.45, n.7, p.1118.

Rezende, Flávio. (2002). Por que reformas administrativas falham? RBCS Vol. 17 № 50 outubro.

Thanassoulis, Emmanuel. (1996). Assessing the efficiency of schools with pupils of different ability using Data Envelopment Analysis. Journal of the Operational Research Society, Vol 47, No 1, pp. 8497,

Varian. Hal R. (1997). Microeconomia: princípios básicos. Rio de janeiro: Atlas.

Recebido em 02/09/2012

Aceito em 14/12/2012 